\title{
The renal excretion of nutrients in pregnancy
}

\author{
F. E. HytTEN \\ M.D., Ph.D., F.R.C.O.G. \\ MRC Reproduction and Growth Unit, Princess Mary Maternity Hospital, \\ Newcastle upon Tyne, NE2 3BD
}

\begin{abstract}
Summary
A feature of normal pregnancy is a huge increase in the excretion of nutrients in urine. Glycosuria is commonplace, and about half of all healthy pregnant women excrete more than when not pregnant. Amounts in excess of $1 \mathrm{~g} / 24 \mathrm{hr}$ are common, and excretion is characteristically intermittent with little apparent relation to plasma levels. Amino acid excretion is also raised four or five times by late pregnancy, with a characteristic pattern for different amino acids, and folate and other water soluble vitamins are similarly squandered. The mechanisms are not understood.
\end{abstract}

THE retention during evolution of an excretory system based on massive blood filtration required the simultaneous development, at least for land animals, of an extremely efficient system for the recovery of blood constituents which the organism could not afford to discard. In general, the recovery arrangements are highly efficient; for example, something of the order of $150 \mathrm{~g}$ of glucose will be filtered through the glomeruli daily by the average person, and yet no more than about $100 \mathrm{mg}$ escapes into the urine, an efficiency of more than $99.9 \%$.

The kidneys are subjected throughout normal pregnancy to a greatly increased plasma flow, more than $700 \mathrm{ml} / \mathrm{min}$ compared to a non-pregnant average of less than $500 \mathrm{ml} / \mathrm{min}$, and the glomerular filtration rate rises in parallel, from less than $100 \mathrm{ml} / \mathrm{min}$ to about $150 \mathrm{ml} / \mathrm{min}$ for the whole of pregnancy. The filtered load of nutrients presented to the tubules in pregnancy, allowing for the fact that the plasma concentration of most nutrients is reduced, is therefore up to $40 \%$ greater than before pregnancy, but an increase of that size is well within the capacity of the tubules, and it is one of the more bizarre and unexpected features of normal pregnancy that relatively large quantities of filtered nutrients are discarded in the urine.

\section{Glucose}

That the pregnant woman commonly excretes detectable glucose in her urine has been recognized for more than a century, and during the 1920 s the provocation of glycosuria by an oral sugar load, or even by a small dose of phlorizin, enjoyed a vogue as a pregnancy test. In a recent study of thirty healthy normal pregnant women, Lind \& Hytten (1972), measured glucose excretion in $24 \mathrm{hr}$ collections of urine, made at intervals from early pregnancy and again 6 weeks post partum. There were large differences, both between women and often in the same woman from time to time. In the non-pregnant (post partum) state all women remained within the usual non-pregnant limit of about $140 \mathrm{mg}$ in $24 \mathrm{hr}$ and four remained within that limit during their pregnancy; the remainder exceeded normal nonpregnant limits during pregnancy; twelve ranged up to $500 \mathrm{mg}$, four up to $1000 \mathrm{mg}$, and the other ten excreted more than $1 \mathrm{~g}$ in $24 \mathrm{hr}$, with one reaching almost $10 \mathrm{~g}$ in one $24 \mathrm{hr}$ collection. In general, there was great irregularity from time to time and, although glycosuria tended to be greater in late pregnancy than in early pregnancy, five of the thirty women showed

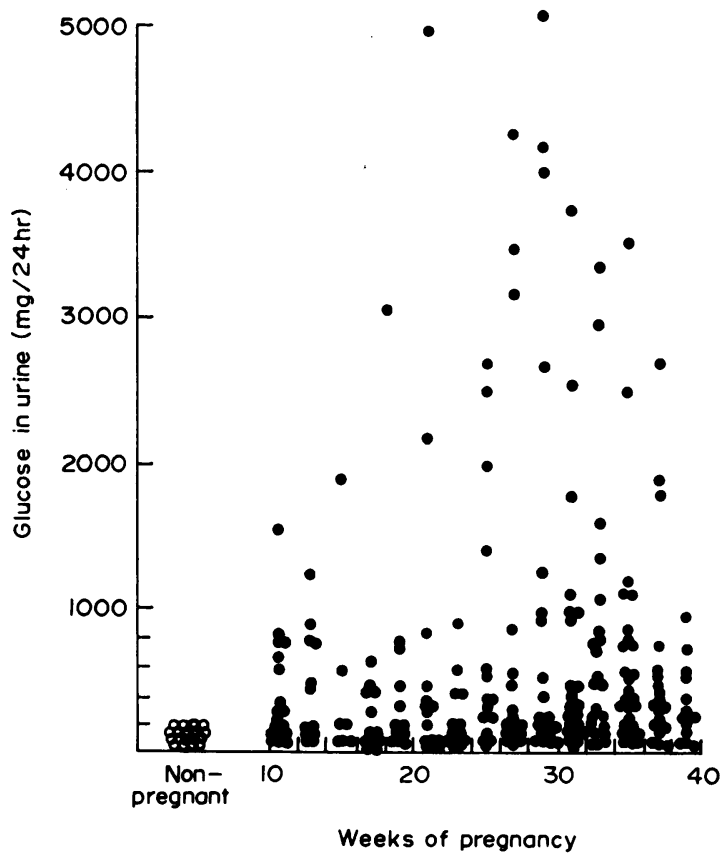

Fig. 1. The overall pattern of glucose excretion in 24-hr samples of urine collected serially in pregnancy from thirty healthy women. 


\begin{tabular}{|c|c|c|c|c|}
\hline \multicolumn{2}{|r|}{ Week 26} & \multicolumn{2}{|r|}{ Week 30} & Week 33 \\
\hline & $0 \quad 0$ & $\overline{0}$ & $0 \bullet \bullet$ & \\
\hline & $\bullet$ & - & - & $-0 \infty$ \\
\hline & - & & 0000 & $0 \cdot \infty$ \\
\hline 0 & $0 \bullet 0 \quad 0$ & & 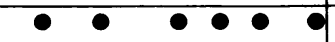 & -0 \\
\hline & - $\infty$ & & $\bullet \bullet \bullet$ & $\bullet \circ \bullet \bullet \bullet \bullet$ \\
\hline & $\begin{array}{llllll}- & 0 & 0 & 0 & 0 & \bullet\end{array}$ & - & - $\bullet$ & - $\bullet$ \\
\hline & $\circ \underset{1250 \mathrm{mg}}{\bullet} \bullet$ & & $\bullet \underset{3717 \mathrm{mg}}{\bullet} \bullet \bullet \bullet$ & $\begin{array}{l}\circ \bullet \bullet \\
686 \mathrm{mg}\end{array} \bullet \bullet$ \\
\hline & Week 35 & & Week 38 & Week 39 \\
\hline 0 & $\begin{array}{llllll}0 & 0 & 0 & 0 & 0 & 0\end{array}$ & & 000000 & 00000000 \\
\hline & 0000000 & & $\begin{array}{llllll}0 & 0 & 0 & 0 & 0 & 0\end{array}$ & 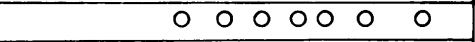 \\
\hline & $\begin{array}{llllll}- & 0 & 0 & 00 & 0 & 0\end{array}$ & & 00000 & \begin{tabular}{llll|}
0000 & 0 & 00 & 0 \\
\end{tabular} \\
\hline 0 & 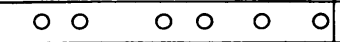 & $\bullet$ & $\begin{array}{lllllll}0 & 0 & 0 & 0 & 0 & 0\end{array}$ & 0000 \\
\hline 0 & $0 \quad 0 \quad 0 \bullet \quad 0 \quad \bullet$ & 0 & $0 \quad \infty 00 \quad 0000$ & $\begin{array}{llllllll}0 & 0 & 0 & 0 & 0 & 0 & 0 & 0 \\
\end{array}$ \\
\hline & $\begin{array}{llllllll}0 & & 0 & 0 & 0 & 0 & 0 & 0\end{array}$ & & 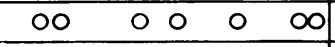 & $0 \quad 0 \quad 0 \quad 0$ \\
\hline 0 & $\begin{array}{lllllll}\circ & 00 & \circ & \circ & 0 & \bullet \\
552 \mathrm{mg} & & & \end{array}$ & & 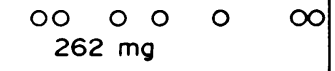 & $\begin{array}{l}\circ 00000000 \\
257 \mathrm{mg}\end{array}$ \\
\hline
\end{tabular}

FIG. 2. The detailed pattern of glycosuria as shown by 'Clinistix' testing of each micturition during each of the last 6 test weeks in one healthy pregnant woman (for detail see text) (from Lind \& Hytten, 1972).

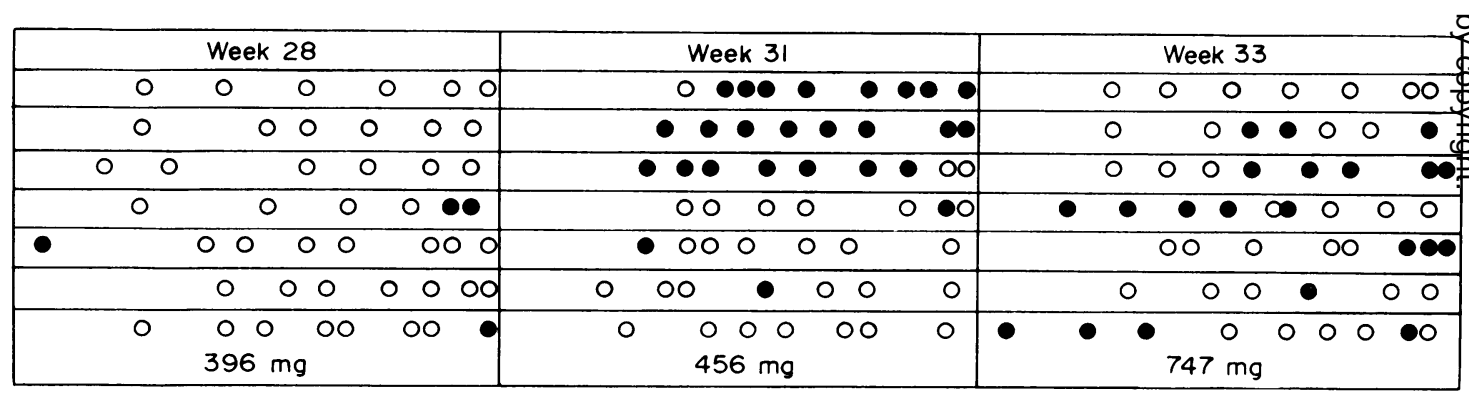

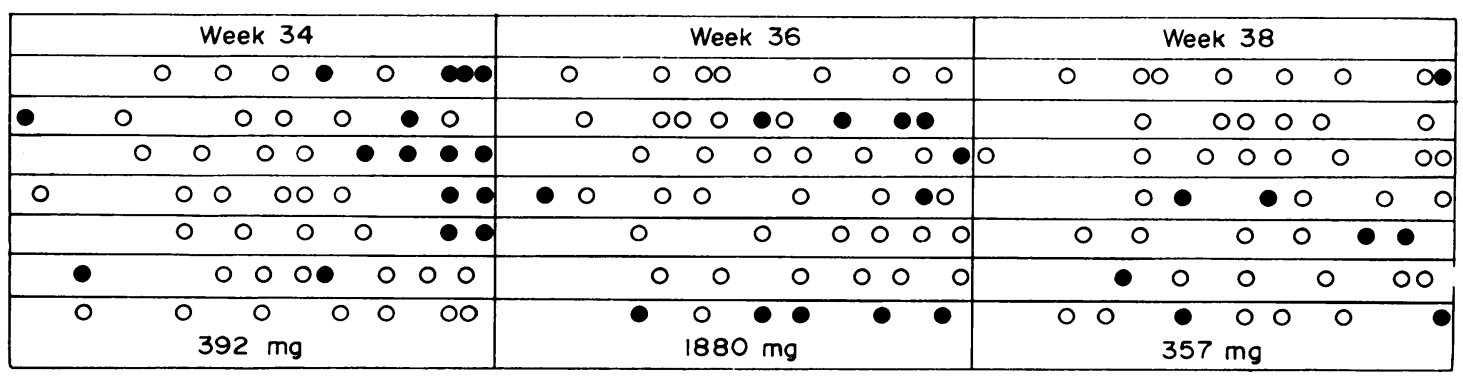

FIG. 3. The detailed pattern of glycosuria as shown by 'Clinistix' testing of each micturition during each of the last 6 test weeks in one healthy pregnant woman (for detail see text) (from Lind \& Hytten, 1972).

their greatest excretion before mid-pregnancy. The overall range is shown in Fig. 1. The pattern of glycosuria in the same women was examined more closely by having them test each passage of urine with paper reagent strips ('Clinistix') for a week before the $24 \mathrm{hr}$ collection. Ten of the thirty never showed detectable glycosuria, but the remaining $\mathrm{N}$ twenty had an enormously variable number of $\underset{2}{0}$ 'positives' during the week's testing.

The kind of variability found is best shown by 6 consecutive weeks of testing at the end of pregnancy in two subjects. In Figs. 2 and 3 each line represents 
a day which is divided into half-hour periods from midnight to midnight, and each micturition is represented by a circle at the appropriate time; filled circles represent positive tests. The seventh day of each week includes a figure for the total glucose excretion on that day. It is clear from these examples that there are periods, parts of days, whole days or groups of days, in which glycosuria is the rule, interspersed by similar periods without glycosuria. In those circumstances it is clearly difficult, if not impossible, to take 'representative' 24-hr samples. Glycosuria occurred somewhat more frequently after meals, particularly in the evening, but there were so many exceptions that no convincing relationship could be postulated, and one is left with an impression of almost random failure of tubular reabsorption.

Any mechanism which might be postulated for the glycosuria of pregnancy must account for the fact that the behaviour of the kidneys of some healthy pregnant women appears to differ little, if at all, from that of non-pregnant subjects, whereas others may, within a few days, vary between the normal non-pregnant performance to reabsorptive failure on a scale which would certainly indicate pathology in a non-pregnant person.

If the intention of testing urine samples for glucose at the ante-natal clinic is to discover women with a potentially serious disorder of carbohydrate metabolism, then it is likely to be a particularly inefficient screening device. The huge majority of pregnant women, even those with heavy glycosuria, have normal oral glucose tolerance tests; more than that, women with unequivocally abnormal glucose tolerance tests may have little or no glycosuria.

\section{Other sugars}

Lactose, presumably manufactured by the mammary gland, increases in amount throughout pregnancy, reaching a mean excretion in a series reported by Date (1964) of $128 \mu \mathrm{g} / \mathrm{min}$. Date also found increased amounts of ribose, xylose and fucose, but not arabinose, in pregnancy urine. Fructose excretion increases similarly (Renschler, Bach \& Baeyer, 1967).

\section{Amino acids}

The excess excretion of amino acids by the pregnant woman has also been recognized for many years - the first report was by Honda in 1923 - but the difficulties of assay have discouraged detailed examination of the phenomenon. A serial study of ten healthy pregnant women by Hytten \& Cheyne (1972) showed that there were three broad patterns of excretion. Glycine, histidine, serine, threonine and alanine are excreted in greatest amounts in the non-pregnant state, and their excretion rises rapidly in early pregnancy to more than double the nonpregnant level by about 16 weeks; thereafter the urinary loss continues to increase until by term it reaches four to five times that of the non-pregnant woman. The excretion of a second group of amino acids, lysine, cystine, taurine, tyrosine, phenylalanine, valine and leucine, also rises rapidly in early pregnancy, but thereafter tends to fall. Of the remaining six amino acids examined, glutamic acid, methionine and ornithine were excreted in marginally greater amounts than before pregnancy; the excretion of asparagine and isoleucine was unchanged and that of arginine tended to fall. Fig. 4 illustrates the mean trends for the two groups where there is a large increase in excretion; the smoothed trends conceal a considerable variation between subjects, and from time to time in the same subject, but all ten women showed the same general pattern.

The increased excretion of amino acids, together with the generally reduced blood levels, means that the renal clearance of amino acids is conspicuously increased. At their peak, the clearances for histidine and glycine, normally about 5 or $6 \mathrm{ml} / \mathrm{min}$, approached $30 \mathrm{ml} / \mathrm{min}$. To put the clearance data in another way, the total quantity of each amino acid filtered at the glomerulus can be calculated by assuming a non-pregnant glomerular filtration rate of $90 \mathrm{ml} / \mathrm{min}$ and a rate in pregnancy of $150 \mathrm{ml} / \mathrm{min}$ (Hytten \& Leitch, 1971). The quantity of each amino acid excreted in the urine can then be expressed as a proportion of the amount filtered. Data in this form for those amino acids with the greatest absolute rate of excretion are shown in Fig. 5, and it can be seen that an average of as much as $20 \%$ of filtered glycine and histidine was lost in the urine in late pregnancy. In some individuals reported by Hytten \& Cheyne



FIG. 4. The excretion of two groups of amino acids in pregnancy by ten healthy women (from Hytten \& Cheyne, 1972). 


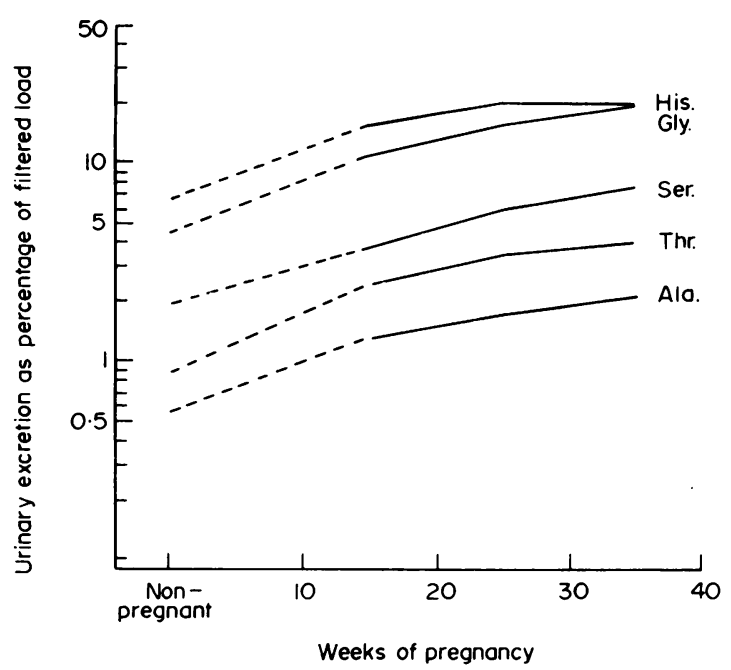

FIG. 5. The excretion of five amino acids expressed as a calculated percentage of the amount filtered by the kidneys.

(1972) glycine was occasionally lost in amounts as high as 9000 to $10,000 \mu \mathrm{mol} / 24 \mathrm{hr}$; with plasma levels of under $100 \mu \mathrm{mol} / 1$, half the filtered load or more was being discarded by the tubules.

The pattern of excretion bears no obvious relation to the biochemical structures of the various amino acids or to their physiological function. Nor is there any suggestion of a selective effect on known transport mechanisms; for example, cystine, ornithine, lysine and arginine share a common carrier for their reabsorption (Dent \& Rose, 1951; Robson \& Rose, 1957) but in pregnancy the pattern of excretion of these four amino acids is quite different. Doolen et al. (1955) showed for non-pregnant subjects that even with large increases in filtered load, the reabsorption of leucine, isoleucine, valine, alanine, arginine, lysine, methionine and phenylalanine is still extremely efficient, so that 'whenever these amino acids are excreted in large amounts, it is more likely due to an impairment of the normal reabsorption mechanism than a saturation phenomenon'. The conclusion must be that the aminoaciduria of normal pregnancy is due to a variable partial failure of the normal reabsorptive mechanisms. The change may be due, at least in part, to the high circulating levels of cortisol in pregnancy (Burke \& Roulet, 1970), since a similar pattern of change can be induced in men by giving $100 \mathrm{mg}$ cortisol daily (Zinneman, Johnson \& Seal, 1963). On the other hand, amino acid excretion increases markedly in early pregnancy before there is any convincing evidence of increased corticosteroid activity.

Water soluble vitamins

It seems likely that most water soluble vitamins which are free in plasma will be excreted in excess in pregnancy, but few have been examined. Lojkin, $\stackrel{\mathbb{Q}}{\stackrel{\Omega}{\triangle}}$ Wertz \& Dietz (1952) reported an increasing excre-.. tion of nicotinic acid, up to twice the non-pregnant $\overrightarrow{\vec{F}}$ average in late pregnancy, and Hytten \& Cheyne (unpublished) found the clearance rate of ascorbic acid to be approximately doubled in pregnancy. The most studied vitamin has been folate. Landon \& Hytten (1971) made a serial study of eight healthy 2 pregnant women, not on supplementary folic acid, and found a substantial increase in folate excretion $\vec{\circ}$ from a non-pregnant mean of $3.5 \mu \mathrm{g} / 24 \mathrm{hr}$ to a mean for the whole of pregnancy of $14.0 \mu \mathrm{g} / 24 \mathrm{hrs}$ (Fig. 6). $\vec{\omega}$ There was considerable individual variation but increased excretion was obvious from before the 0 end of the first trimester and excretions over $50 \mu \mathrm{g} / \stackrel{3}{3}$. $24 \mathrm{hr}$ were recorded. Since plasma levels of folate are $\overrightarrow{0}$ considerably reduced in pregnancy the filtered load of of folate is probably no greater than before preg- $\mathrm{N}$ nancy, so the increased excretion must again be N attributed to a failure of the tubules to reabsorb. Fleming (1972) has found confirmatory evidence of reabsorptive failure.

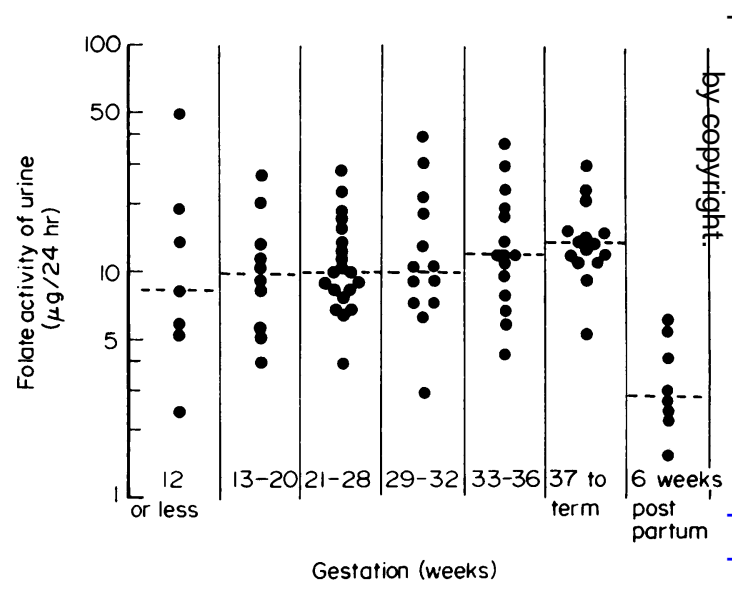

FIG. 6. The excretion of folate in pregnancy by eight healthy women (from Landon \& Hytten, 1971).

Apart from providing diagnostic pitfalls, the clinical importance of the raised nutrient excretion in pregnancy is difficult to assess. Losses of $50 \mu \mathrm{g}$ of $\supset$ folate, or of $2 \mathrm{~g}$ of amino acids, daily might be a $\frac{}{0}$ serious erosion of reserves in parts of the world where folate and protein intake is marginal, but it $\tilde{N}$ is not known whether the kidney is capable of $N$ economies under these circumstances.

An important practical consequence of the high nutrient content of the urine is its increased value as a culture medium for bacteria (Roberts \& Beard, 1965). That, together with a tendency to stasis in $\$$ the urinary tract, may explain the increased liability to urinary tract infection in pregnancy. 


\section{References}

BURKe, C.W. \& Roulet, F. (1970) Increased exposure of tissues to cortisol in late pregnancy. British Medical Journal, 1, 657.

DATE, J.W. (1964) The excretion of lactose and some monosaccharides during pregnancy and lactation. Scandinavian Journal of Clinical and Laboratory Investigation, 16, 589.

Dent, C.E. \& Rose, G.A. (1951) Aminoacid metabolism in cystinuria. Quarterly Journal of Medicine, 20, 205.

Doolen, P.D., Harper, H.A., Hutchin, M.E. \& Shreeve, W.W. (1955) Renal clearance of eighteen individual amino acids in human subjects. Journal of Clinical Investigation, 34, 1247.

FLEMING, A.F. (1972) Urinary excretion of folate in pregnancy. Journal of Obstetrics and Gynaecology of the British Commonwealth, 79, 916.

HoNDA, M. (1923) Untersuchung des Harns Gravider Frauen. III-Mitteilung. Journal of Biochemistry (Tokyo), 2, 351.

HytTEN, F.E. \& CHEYNE, G.A. (1972) The aminoaciduria of pregnancy. Journal of Obstetrics and Gynaecology of the British Commonwealth, 79, 424.

Hytten, F.E. \& Leitch, I. (1971) The Physiology of Human Pregnancy, 2nd edn, p. 146. Blackwell Scientific Publications, Oxford.
LANDON, M.J. \& HyTten, F.E. (1971) The excretion of folate in pregnancy. Journal of Obstetrics and Gynaecology of the British Commonwealth, 78, 769.

Lind, T. \& HytTEN, F.E. (1972) The excretion of glucose during normal pregnancy. Journal of Obstetrics and Gynaecology of the British Commonwealth, 79, 961.

Lojkin, M.E., Wertz, A.W. \& Dietz, C.G. (1952) Metabolism of nicotinic acid in pregnancy. Journal of Nutrition, 46, 335.

RenSChleR, H.E., BaCH, H.G. \& BAEyer, H. (1967) The urinary excretion of glucose in normal pregnancy. German Medical Monthly, 12, 24.

RoBerTS, A.P. \& BEARD, R.W. (1965) Some factors affecting bacterial invasion of bladder during pregnancy. Lancet, $\mathbf{i}$, 1133.

RoBSon, E.B. \& Rose, G.A. (1957) The effect of intravenous lysine on the renal clearances of cystine, arginine and ornithine in normal subjects, in patients with cystinuria and Fanconi syndrome and in their relatives. Clinical Science, 16, 75.

Zinneman, H.H., Johnson, J.J. \& Seal, U.S. (1963) Effect of short-term therapy with cortisol on the urinary excretion of free amino acids. Journal of Clinical Endocrinology, 23, 996. 